\title{
STUDIES OF BREATHING, PULMONARY VENTILATION AND \\ SUBJECTIVE AWARENESS OF SHORTNESS OF BREATH \\ (DYSPNEA) IN NEUROCIRCULATORY ASTHENIA, EFFORT SYNDROME, ANXIETY NEUROSIS ${ }^{1}$
}

\author{
By MANDEL E. COHEN ANd PAUL D. WHITE \\ (From the Medical and Psychiatric Clinics and the Cardiac Research Laboratory of the Massa- \\ chusetts General Hospital, Departments of Medicine and Diseases of the Nervous \\ System, Harvard Medical School)
}

(Received for publication December 23, 1946)

Patients with neurocirculatory asthenia (N. C.A.), anxiety neurosis, or effort syndrome commonly complain of shortness of breath, inability to draw a satisfactory breath, and incapacity for work caused by breathlessness. Such symptoms have been noted in the classic works on this subject by DaCosta (1) and Sir Thomas Lewis (2) among others.

The present report deals with studies carried out to investigate in a quantitative way characteristics of breathing in N.C.A. These studies included investigations of (1) patients' symptoms as compared with those of control subjects; (2) study of characteristics of breathing at rest, including respiratory rate, minute respiratory volume, tidal air, oxygen consumption, incidence of sighs, variation in respiratory rate and in respiratory depth; (3) studies of breathing during exercise, of ventilation index, and of the relation of ventilation index to awareness of shortness of breath, i.e., dyspnea; (4) studies of ventilation and ventilatory efficiency while walking and running on a treadmill. Details of technique will be described in each section.

In general, studies were done on 74 patients with chronic N.C.A. and on 27 patients with acute N.C.A. These two groups of patients were differentiated on grounds of history alone (3). Those who had a lifelong course and could never do hard work or athletics were designated as chronic N.C.A. Those who gave convincing evidence of good health, ability to do muscular work or athletics, and emotional stability previous to the de-

1 This work was done under contract recommended by the Committee of Medical Research of the Office of Scientific Research and Development and the Massachusetts General Hospital.

With the technical assistance of Mary P. Lennon, Audrey Y. Dennison, and Jane R. Brown. velopment of illness were designated as acute N.C.A. In addition to studies related to breathing the patients were subjected to a wide variety of other tests which are reported elsewhere (3).

For control subjects we used 129 healthy subjects, of whom 117 were soldiers, and 25 soldiers who were convalescing from infected war wounds.

\section{Incidence of symptoms}

Method. A series of questions was administered to 74 patients with chronic N.C.A., 25 patients with acute N.C.A., 25 convalescent controls, and 55 healthy control subjects. The presence of the symptom was noted on a printed check list by plus, the absence by zero.

In addition, during the 20 -inch step test $(4,5)$, patients and control subjects were asked to perform for 5 minutes at the pace of 30 trips per minute for a maximum of 5 minutes. The subjects were asked what stopped them when they did not go on for the full 5 minutes. The incidence of breathlessness among other symptoms was tabulated for control subjects and patients.

Results. The incidence in N.C.A. of symptoms involving breathing is presented in Table $\mathrm{I}$, which shows that there is a high incidence of symptoms related to breathing in N.C.A. It is of further note that there is consistently, for each symptom, a higher incidence in the chronic N.C.A. group than in the acute; there is a slightly greater incidence of such symptoms as breathlessness and inability to get a satisfactory breath in convalescent subjects as compared to healthy controls.

The feeling of breathlessness may be present at any time in the patients. In addition, patients commonly have the feeling that they do not breathe in a satisfactory manner, that they do not get in enough air while breathing, or that their breathing does them no good.

Difficulties in breathing are quite marked when the patients attempt to wear a gas mask or while they are attempting to swim. 
TABLE I

Incidence in neurocirculatory asthenia of symptoms involving breathing *

\begin{tabular}{|c|c|c|c|c|}
\hline \multirow{2}{*}{ Group studied } & \multicolumn{2}{|c|}{$\begin{array}{c}\text { Patients with } \\
\text { N.C.A. }\end{array}$} & \multicolumn{2}{|c|}{ Controls } \\
\hline & Chronic & Acute & Conv. & Healthy \\
\hline Number of subjects & 74 & 25 & 25 & 55 \\
\hline
\end{tabular}

From present illness

\begin{tabular}{l|r|r|r|r}
\hline 1. Breathlessness & 99 & 79 & 24 & 13 \\
2. Inability to get a satisfac- & 74 & 41 & 16 & 2 \\
tory breath & 62 & 52 & 4 & 5 \\
3. Panting & 61 & 39 & 12 & 9 \\
4. Sighing & 55 & 17 & 12 & 15 \\
5. Gas mask trouble & 50 & 28 & 8 & 5 \\
6. Smothering & & \\
\hline
\end{tabular}

From past history

\begin{tabular}{l|r|r|r|r}
\hline 7. Trouble breathing in water & 75 & 22 & 12 & 10 \\
$\begin{array}{l}\text { (while swimming) } \\
\text { 8. Always short of breath }\end{array}$ & 41 & 0 & 8 & 7 \\
\hline
\end{tabular}

During hard work test

9. Breathlessness severe enough to cause patients to stop

* Significance of differences in incidence of symptoms: Chronic N.C.A. vs. healthy controls-all differences significant; chronic N.C.A. vs. acute N.C.A.-all differences significant except for 3,4 and 6; chronic N.C.A. vs. convalescent controls - all differences significant; acute N.C.A. vs. convalescent control subjects-all differences significant except 2, 5, 6 and 7; acute N.C.A. vs. healthy control subjects -all differences significant except for 5 and 7; convalescent control subjects vs. healthy control subjectsonly 2 show significant difference.

When patients and subjects, were questioned as to what stopped them in the 20 -inch step test, 60 per cent of the patients reported that they were winded or that their wind gave out, in contrast to 18 per cent of the healthy controls. This was true even though the healthy controls lasted much longer in the performance of the test.

Sum MARY. N.C.A. patients have many complaints referable to breathing; symptoms are of higher incidence in chronic N.C.A. When questioned at the end of hard exercise, many N.C.A. patients state that shortness of breath causes them to stop before the test is finished.

\section{Studies of characteristics of breathing at rest}

METHOD. Respiratory measurements were made after 30 minutes rest, in a fasting condition and while breathing oxygen, in 50 men with N.C.A. and in 34 healthy men. The usual procedure for doing a basal metabolic rate test was employed (6) using a 12-minute record. The measurements were as follows: (1) Minute respiratory volume in liters of oxygen breathed per minute-this was obtained by measuring each inspirational length in a minute, multiplying the sum by the appropriate calibration factor. (2) Minute respiratory volume was adjusted for body surface by dividing by surface area obtained from height and weight tables (7). (3) Respiratory rate was counted in breaths per minute. (4) Tidal air was calculated for each minute by dividing ventilation per minute by respiratory rate per minute. The mean tidal air for the record was obtained from averaging the tidal air for each minute. (5) Tidal air was also adjusted for body surface by dividing the mean tidal air for each patient by his surface area. (6) A sigh was defined for purposes of this study as an inspiration which was at least $21 / 2$ times the depth of the previous inspiration if it was representative; if not, the first such breath in that minute was used as a basis of comparison. (7) Basal metabolic rate was calculated in the usual manner (6). (8) Coefficient of variation was calculated for rate in each patient by dividing the standard deviation of respiratory rate by the mean respiratory rate. Table II presents the mean of the coefficient of variation for respiratory rate. (9) Coefficient of variation for depth of inspiration was obtained by dividing standard deviation of the depths of inspiration for 6 minutes by the mean inspiratory depth (tidal air). The latter two measurements were made to discover whether the breathing of patients with N.C.A. was more irregular in rate and in inspiratory depth than was true of healthy control subjects.

Results. Table II shows that minute respiratory volume and oxygen consumption are the same for the two groups. However, respiratory rate is definitely more rapid in patients, and the breathing in patients is more shallow. This is true even after adjusting for differences in body size. Sighing is more frequent in patients than in control subjects, but not significantly so in this series.

Summary. N.C.A. patients resting, fasting, and breathing oxygen as compared with healthy control subjects show: (1) a higher respiratory rate, (2) shallow breathing, (3) a greater coeffcient of variation in depth of inspiration.

\section{Studies of ventilation index and its relation to awareness of shortness of breath (dyspnea)}

Since the feeling of breathlessness (dyspnea) was almost universal in N.C.A., investigations were conducted to reveal more about the nature of this symptom. We particularly wished to learn the answers to the following questions. (1) Does 
TABLE II

Breathing measurements

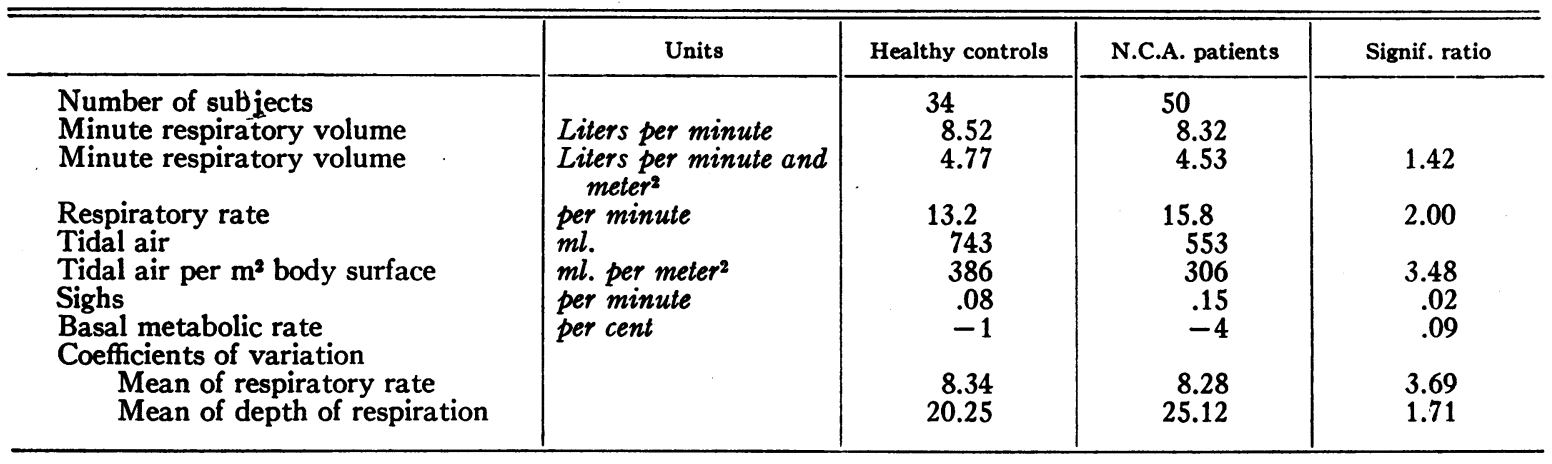

the feeling of shortness of breath correlate with measurable changes in ventilation or vital capacity, the usual correlates of dyspnea $(8,9)$ ? (2) Do patients with N.C.A. show differences in minute respiratory volume during and after comparable amounts of varying degrees of exercise as compared with healthy control subjects? (3) Is ventilation index, an objective measure proposed by Harrison and associates (10) as a quantitative objective correlate of dyspnea, abnormal in N.C.A.? (4) Do N.C.A. patients develop dyspnea at an abnormal level of ventilation index?

Method. Ventilation index studies described by Harrison and associates (10) were done in 58 patients with N.C.A. and in $\mathbf{5 5}$ healthy soldiers. Formula for ventilation index is :

Ventilation index $=\frac{\text { ventilation }}{\text { vital capacity }} \times \frac{1+\frac{\text { ideal weight }}{\text { actual weight }}}{2}$.

All control subjects were healthy American soldiers. The N.C.A. patients consisted of 33 soldiers, 16 sailors, 2 marines, and 7 civilians. There were 41 cases of chronic N.C.A. and 17 of acute N.C.A.

The test was carried out by having the subject walk over a set of steps with measurements of ventilation before, during, and after the exercise. The steps used have been described by Harrison and have the following measurements : low step $17 \mathrm{~cm}$., high step $32 \mathrm{~cm}$., length of platform $64 \mathrm{~cm}$.

The patient was given a demonstration of the 4 paces of the test. He practiced a few steps at each pace in order to familiarize himself with the steps. He then sat in an Adirondack reclining chair for 30 minutes. At the end of this period the patient was connected to the Tissot spirometer. The resting ventilation for 3 minutes was measured along with pulse rate and respiratory rate. The exercise then proceeded for 2 minutes and the patient then rested for a 5-minute recovery period, the ventilation being measured continuously during this 7 -minute period (comprising 2 minutes exercise and 5 minutes recovery period). The pace of the step test was regulated by a metronome. The first exercise consisted of 6 trips, the second of 12 trips, the third of 16 trips, and the fourth of 24 trips in 2 minutes. One observer, using a stopwatch, counted off the pace for the patient, slowed him down or speeded him up if he lost the pace, held the tubing connecting him to the Tissot to avoid his being entangled in it, and for certainty checked the number of trips with a Veeder counter. Second observer read and recorded the Tissot units and also counted respiratory rate during the test.

Pulse recovery rate was determined also by the first observer. The pulse was counted after the patient sat down from 1 to $1 \frac{1}{2}$ minutes, 2 to $2 \frac{1}{2}$ minutes, and 4 to $4 \frac{1}{2}$ minutes. At the end of each 5-minute recovery period the patient was confronted with a printed card with the questions: Were you short of breath? Not at all? A little? Moderately? Severely? Were you very uncomfortable or did you feel distress? Yes or No. The patient was asked to point out the answer to each question which described best his subjective feelings during the test. In addition to this, one of the observers tried to estimate whether the patient seemed to be in respiratory distress -slightly, moderately, severely, or not at all. During the 1 minute between tests when the patient reported his subjective feelings by pointing to the question card, the Tissot level was readjusted, if necessary; the metronome was set to the next speed; and the patient was asked to stand about 15 seconds before the beginning of the next test. Then the next exercise began.

Vital capacity was determined on the patient in a sitting position. This was carried out by the method previously described (11), the highest of 3 determinations checking within $50 \mathrm{ml}$. being accepted. Age, height, and weight of the patient were determined and surface area was taken from standard Benedict-Roth tables (7). Room temperature, Tissot temperature, and barometric pressure were recorded.

Results. Ventilation index: Figure 1 shows that for each exercise the mean Ventilation Index is higher in the N.C.A. patients than it is in the healthy control subjects. The differences between 


\section{VENTILATION INDEX}

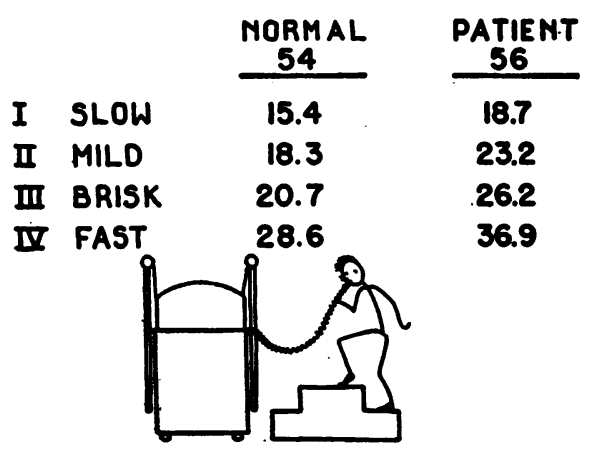

FIG. 1

The means of ventilation index for 56 N.C.A. patients as compared with 54 control subjects are compared above, for the 4 paces of exercise. The ventilation index is significantly higher in N.C.A. for each exercise. The differences were progressively greater as the speed of exercise increased. The figure illustrates schematically the patient during exercise breathing to the Tissot spirometer.

the controls and the patients are statistically significant (see Tables III and IV).

It is of further interest that patients with chronic N.C.A. show higher ventilation indices than do

TABLE III

Ventilation index-means and statistics in neurocirculatory asthenia and healthy controls

\begin{tabular}{|c|c|c|c|c|c|c|c|c|c|c|c|}
\hline \multirow{2}{*}{$\begin{array}{l}\text { Ex- } \\
\text { er- } \\
\text { cise }\end{array}$} & \multirow{2}{*}{ No } & \multicolumn{2}{|c|}{ Controls } & \multirow{2}{*}{ S.E. } & \multirow{2}{*}{ No. } & \multicolumn{2}{|c|}{ N.C.A. } & \multirow{2}{*}{ S.E. } & \multirow{2}{*}{ 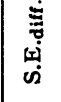 } & \multirow{2}{*}{$\begin{array}{l}\text { Sig- } \\
\text { nif. } \\
\text { ratio }\end{array}$} & \multirow{2}{*}{ Odds } \\
\hline & & V.I. & 6 & & & V.I. & 6 & & & & \\
\hline $\begin{array}{l}\text { II } \\
\text { III } \\
\text { IV }\end{array}$ & $\begin{array}{l}53 \\
54 \\
54 \\
54\end{array}$ & $\begin{array}{l}15.4 \\
18.3 \\
20.7 \\
28.6\end{array}$ & $\begin{array}{l}2.39 \\
2.39 \\
2.81 \\
4.11\end{array}$ & $\begin{array}{l}.328 \\
.325 \\
.383 \\
.559\end{array}$ & $\begin{array}{l}56 \\
56 \\
56 \\
56\end{array}$ & $\begin{array}{l}18.7 \\
23.2 \\
26.2 \\
36.9\end{array}$ & $\begin{array}{r}6.67 \\
9.09 \\
10.35 \\
13.15\end{array}$ & $\begin{array}{r}.892 \\
1.216 \\
1.383 \\
1.758\end{array}$ & $\begin{array}{r}.950 \\
1.257 \\
1.435 \\
1.849\end{array}$ & $\begin{array}{l}3.53 \\
3.86 \\
3.85 \\
4.50\end{array}$ & $\begin{array}{r}2,200-1 \\
8,000-1 \\
8,000-1 \\
20,000-1\end{array}$ \\
\hline
\end{tabular}

No. = number of subjects exercised; V.I. = Ventilation Index; $6=$ Standard deviation of the observations in the sample; S.E. = the standard error of the mean; S.E.diff. = standard error of the difference between the two means; Significance ratio $=$ S.E.diff. $\div$ difference between means; Odds = the probability of the difference arising once in this number of times by chance.

TABLE IV

Ventilation index

Acute N.C.A. (17 cases) compared with chronic N.C.A. (39 cases)

\begin{tabular}{l|c|c}
\hline \hline & Acute N.C.A. & Chronic N.C.A. \\
\hline Exercise I & 16.9 & 19.6 \\
Exercise II & 21.4 & 24.0 \\
Exercise III & 23.9 & 27.3 \\
Exercise IV 、 & 34.7 & 37.9 \\
\hline
\end{tabular}

patients with acute N.C.A., this difference being consistent for all 4 exercises.

Vital capacity: The high ventilation index in N.C.A. is not due to abnormal vital capacity, as vital capacity in N.C.A. does not differ from vital capacity of healthy control subjects of similar size ; Table $\mathrm{V}$ shows that the vital capacity in $\mathrm{ml}$. and per square meter of body surface is 2,419 for healthy control subjects, 2,426 for N.C.A. patients.

TABLE $v$

Vital capacity

(Neurocirculatory asthenia vs. healthy controls)

\begin{tabular}{l|c|c|c}
\hline \hline & Number & v.c. & v.c. \\
\hline & & $m l$. & $m l . M^{2}$ \\
Controls & 54 & $4,443.3$ & $2,419.4$ \\
N.C.A. & 54 & $4,395.1$ & $2,425.5$ \\
\hline
\end{tabular}

Vital Capacity-Standard Error of Difference between means $=.92 ;$ significance ratio $=.52$. Vital Capacity per meter squared of body surface-Standard Error of Difference between means $=50.9$; significance ratio $=.12$. Thus, neither the slight differences in vital capacity nor those in vital capacity per $M^{2}$ between N.C.A. and controls are statistically significant.

The slight differences in vital capacity between N.C.A. and healthy controls are obviously not significant. The significance ratio of the differences for vital capacity is .52 , for vital capacity per square meter is .12 .

Although vital capacities were the same in value in the two groups, it was of interest that more trials were required to obtain 3 checking values in N.C.A. A mean of 3.3 extra trials was required to check the controls, as against 5.44 extra trials for patients. This difference was significant, significance ratio being 2.36. Two controls and 12 patients never checked within $50 \mathrm{ml}$.; in those we used the highest value for calculation purposes.

Total ventilation during and after exercise: The total of ventilation ( 2 minutes during and $5 \mathrm{~min}$ utes of recovery after exercise) is shown in Table $\mathrm{V}$ to be higher for each exercise, in N.C.A. than in healthy control subjects. The mean ventilations in liters for 7 minutes are: Exercise I-Controls 72.3, N.C.A. 85.2; Exercise $I I$-Controls 86.0, N.C.A. 105.8; Exercise III-Controls 97.2, N.C.A. 119.8; Exercise IV-Controls 134.2, N.C.A. 169.8. The differences between N.C.A. cases and controls become greater as the exercise pace increases. 
The difference in ventilation index between N.C.A. and control subjects is thus due to the ventilation factor, not to the vital capacity factor.

Minute respiratory volume during and after exercise: Figure 2 shows that for each minute during and after exercise the mean minute respiratory volume is higher in N.C.A. than in healthy controls. The differences become greater as the

\section{VENTILATION DURING AND AFTER EXERCISE}

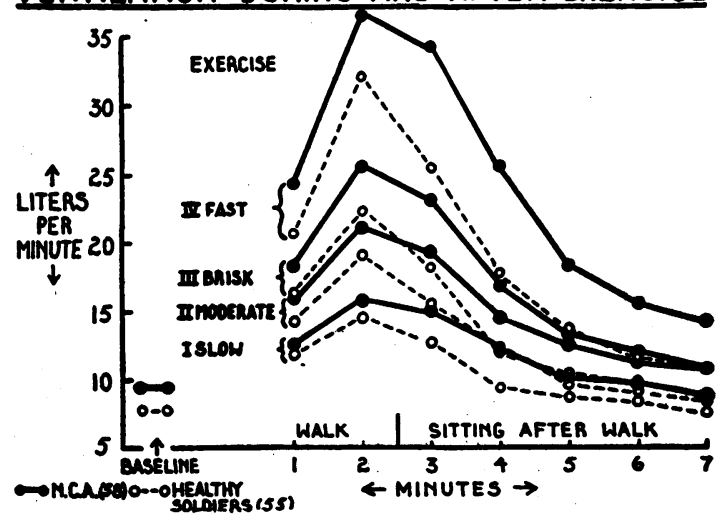

FIG. 2

The ordinate, shows liters per minute of pulmonary ventilation; on the abscissa are marked off the time intervals during 2 minutes of exercise and 5 minutes of recovery. For all minutes and all exercises the patients show higher minute respiratory volume than do the controls.

\section{DIFFERENCES BETWEEN VENTILATION MEANS (M.C.A. vs. HEALTHY SOLDIERS)}

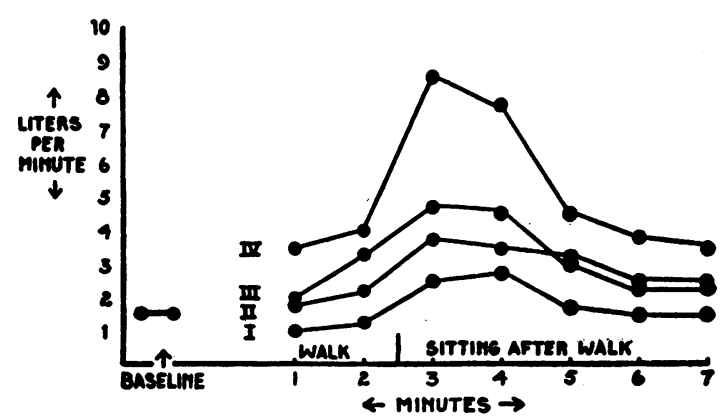

FIG. 3

The ordinate shows the excess between minute respiratory volume for each minute and each exercise in N.C.A. The abscissa marks off the difference at rest (baseline), and the time intervals during 2 minutes of exercise and 5 minutes of recovery. Roman numerals indicate progressively increasing speeds of exercise. The differences are more marked in the early recovery period.

\section{PERCENTAGE DIFFEREMCE BETWEEN VENTILATION MEANS (M.CA. vS. HEALTHY SOLDIERS)}

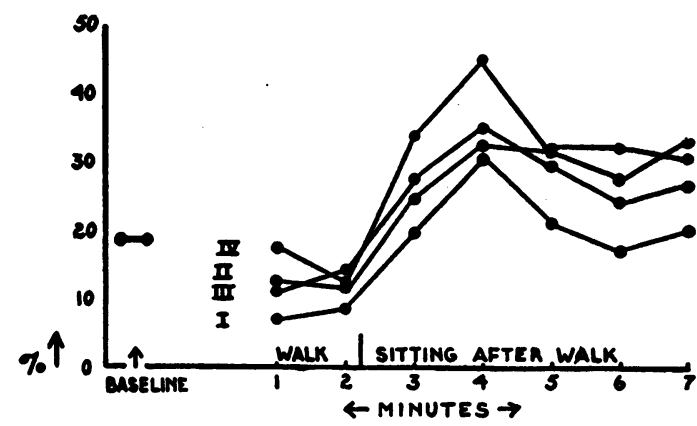

FIG. 4

The ordinate shows the percentage difference between ventilation means of N.C.A. and controls, using the controls as a basis of comparison, for each minute and each exercise. The abscissa marks off the time intervals, baseline indicating the initial resting value, and the time intervals during 2 minutes of exercise and 5 minutes of recovery. Roman numerals indicate progressively increasing speeds of exercise. The percentage differences are more marked in the early recovery period.

pace of exercise becomes more rapid. Figures 2 and 3 further illustrate that the differences are more marked after exercise than during exercise. The percentage difference between the mean ventilation in N.C.A. and in healthy control subjects, using the mean ventilation of the healthy subjects for that minute as a baseline, reaches its peak dur. ing the second recovery minute, as shown in Figure 4.

Respiratory rate and tidal air: The respiratory rate was greater in N.C.A. than in controls. Table VI shows that this is true during the preliminary baseline observations and for each exercise, the data for the fourth minute (i.e., second recovery

TABLE VI

Respiratory rate and tidal air

During 4th minute of test, i.e., 2nd recovery minute

\begin{tabular}{|c|c|c|c|c|c|c|}
\hline \multirow{2}{*}{ Exercise } & \multicolumn{2}{|c|}{ Number } & \multicolumn{2}{|c|}{ Respiratory rate } & \multicolumn{2}{|c|}{ Tidal air } \\
\hline & Controls & N.C.A. & Controls & N.C.A. & Controls & N.C.A. \\
\hline $\begin{array}{c}\text { Baseline } \\
\text { I } \\
\text { II } \\
\text { III } \\
\text { IV }\end{array}$ & $\begin{array}{l}53 \\
31 \\
28 \\
26 \\
37\end{array}$ & $\begin{array}{l}49 \\
55 \\
54 \\
52 \\
51\end{array}$ & \begin{tabular}{|c|} 
per $m$ \\
15.3 \\
15.4 \\
16.5 \\
16.2 \\
17.6
\end{tabular} & \begin{tabular}{|l|}
17.2 \\
18.4 \\
20.4 \\
21.3 \\
22.9
\end{tabular} & \begin{tabular}{|c|}
\multicolumn{2}{c}{ ml. pe } \\
293 \\
343 \\
386 \\
423 \\
583
\end{tabular} & $\begin{array}{l}M^{2} \\
317 \\
377 \\
420 \\
460 \\
634\end{array}$ \\
\hline
\end{tabular}


TABLE VII

Dyspnea, distress, and exercise in 55 N.C.A. patients and 54 control subjects Degrees of dyspnea associated with each rate of exercise (per cent incidence-degrees of dyspnea)

\begin{tabular}{l|c|c|c|c|c|c|c|c}
\hline & \multicolumn{3}{|c|}{ None } & \multicolumn{2}{c|}{ Slight } & \multicolumn{2}{c|}{ Moderate } & \multicolumn{2}{c}{ Severe } \\
\cline { 2 - 7 } & Controls & N.C.A. & Controls & N.C.A. & Controls & N.C.A. & Controls & N.C.A. \\
\hline Exercise I & 83 & 29 & 13 & 49 & 4 & 18 & 0 & 4 \\
Exercise II & 67 & 9 & 26 & 40 & 6 & 38 & 0 & 13 \\
Exercise III & 54 & 8 & 37 & 31 & 9 & 45 & 0 & 16 \\
Exercise IV & 26 & 4 & 33 & 14 & 33 & 24 & 7 & 58 \\
\hline
\end{tabular}

Per cent incidence of dyspnea and of distress or discomfort associated with each rate of exercise

\begin{tabular}{|c|c|c|c|c|c|c|}
\hline & \multicolumn{3}{|c|}{ Dyspnea } & \multicolumn{3}{|c|}{ Distress } \\
\hline & Controls & N.C.A. & $\begin{array}{l}\text { Significance } \\
\text { ratio }\end{array}$ & Controls & N.C.A. & $\underset{\text { ratio }}{\text { Significance }}$ \\
\hline $\begin{array}{l}\text { Exercise I } \\
\text { Exercise II } \\
\text { Exercise III } \\
\text { Exercise IV }\end{array}$ & $\begin{array}{l}17 \\
31 \\
46 \\
74\end{array}$ & $\begin{array}{l}71 \\
91 \\
92 \\
96\end{array}$ & $\begin{array}{l}3.5 \\
3.9 \\
3.8 \\
4.5\end{array}$ & $\begin{array}{r}9 \\
14 \\
14 \\
25\end{array}$ & $\begin{array}{l}30 \\
61 \\
67 \\
73\end{array}$ & $\begin{array}{l}2.6 \\
5.2 \\
6.0 \\
5.1\end{array}$ \\
\hline
\end{tabular}

minute) being presented. Table VI also shows that the tidal air, adjusted for body size, is greater in N.C.A. during the recovery period after each exercise.

Calculation reveals that the maximum percentage rise in respiratory rate is 33 per cent in N.C.A. as compared with 15 per cent in controls; the maximum rise in tidal air is 100 per cent in N.C.A. as compared with 99 per cent in controls. This shows that the differences in minute respiratory volume between N.C.A. and controls are largely due to the disproportionate rise in respiratory rate in N.C.A. The maximum difference in tidal air during this time interval between N.C.A. and controls is 10 per cent, in respiratory rate 32 per cent.

Subjects' awareness of dyspnea and distress as related to level of ventilation index (see Table VII) : Table VIII shows that for the same range

TABLE VIII

Percentage incidence of "dyspnea" and "distress" at ventilation indices 15 through 25

\begin{tabular}{|c|c|c|c|c|c|}
\hline & \multicolumn{4}{|c|}{ Shortness of breath } & \multirow{2}{*}{ Distress } \\
\hline & None & Slight & $\underset{\text { ate }}{\text { Moder- }}$ & Severe & \\
\hline $\begin{array}{l}\text { Controls } \\
\text { N.C.A. }\end{array}$ & $\begin{array}{l}63 \\
13\end{array}$ & $\begin{array}{l}28 \\
49\end{array}$ & $\begin{array}{r}8 \\
32\end{array}$ & $\begin{array}{r}1 \\
68\end{array}$ & $\begin{array}{l}15 \\
51\end{array}$ \\
\hline
\end{tabular}

of ventilation index a higher incidence of patients reports shortness of breath and distress or discomfort as compared with controls. Not only do more patients feel shortness of breath but they also report feeling a greater degree of shortness of breath. For example, at this level of ventilation index 68 per cent of N.C.A. patients felt severe shortness of breath in contrast to only 1 per cent of healthy controls.

This demonstrates that at the same level of ventilation index, the "objective correlate of dyspnea," more patients feel distress and shortness of breath, and to a greater degree, than do control subjects. This shows that the incidence and degree of dyspnea in N.C.A. is not only out of proportion to the amount of exercise, but also is out of proportion to the amount of ventilation and ventilation index.

Appearance of objective respiratory distress: Table IX shows that by our impressionistic method of estimating the presence and degree of objective respiratory distress N.C.A. patients showed a higher incidence of objective respiratory distress than controls for the same amount of exercise. At the same amount of ventilation index, the patients exhibited a higher incidence of appearance of objective respiratory distress with a greater degree of it. 
TABLE IX

Appearance of respiratory objective distress in 54 N.C.A. patients and 54 healthy controls

Percentage incidence of appearance of objective distress during each exercise

\begin{tabular}{c|c|c}
\hline \hline Exercise & Controls & N.C.A. \\
\hline I & 11 & 58 \\
II & 33 & 91 \\
II & 50 & 96 \\
& 89 & 100 \\
\hline
\end{tabular}

Percentage incidence of appearance of objective distress and its severity for ventilation indices 15 through 25

\begin{tabular}{l|c|c|c|c}
\hline & \multicolumn{4}{|c}{$\begin{array}{c}\text { Percentage incidence of appearance of objective } \\
\text { respiratory distress }\end{array}$} \\
\cline { 2 - 5 } & None & Slight & Moderate & Severe \\
\hline Controls & 60 & 29 & 11 & 0 \\
N.C.A. & 19 & 58 & 21 & 9 \\
\hline
\end{tabular}

When we compared our estimates of the 3 degrees of severity of objective breathlessness with the 3 degrees of the patients' subjective reports, there was noted a tendency for the patients to report feeling more than we estimated, for the controls to report less. This comparison is obviously impressionistic, and this must be taken into consideration when evaluating this type of data.

Summary. 1. Ventilation index is higher in patients for each exercise than in controls, the difference becoming greater as the rate and amount of exercise increase.

2. Vital capacity does not differ from that of controls.

3. Total pulmonary ventilation is higher, during and after exercise, the difference being greater as the rate and amount of exercise increase.

4. The high ventilation index in N.C.A. is due to the high ventilation, therefore, and not to the vital capacity factor.

5. The resting minute respiratory volume, with persons seated and breathing air, is slightly but significantly higher in patients.

6. Minute respiratory volume is higher in N.C.A. for each minute and for each exercise. The greatest minute respiratory volumes are noted at the beginning of the recovery periods, not during the exercise.

7. Both respiratory rate and tidal air are higher in N.C.A. than in controls, as judged from the second recovery minute.
8. The differences in minute respiratory volume between N.C.A. and controls are largely due to the disproportionate rise in respiratory rate in N.C.A.

9. For the same amount and rate of exercise patients complain in higher incidence and of a greater degree of shortness of breath than do controls.

10. For the same amount and rate of exercise patients complain in higher incidence of distress and discomfort.

11. For the same amount and rate of exercise more patients exhibited objective respiratory distress than did controls.

12. For the same level of ventilation index more patients exhibited objective respiratory distress than did controls.

13. In comparing our estimates of patients' objective respiratory distress with patients' subjective reports, there was noted a tendency for the patients to report more than we estimated, for the controls to report less.

14. Both the awareness of and outward appearance of shortness of breath are related in N.C.A. to some factor or factors other than amount of pulmonary ventilation.

\section{Breathing while walking and running on a treadmill}

METHOD. Ventilation and ventilatory efficiency were studied in N.C.A. patients while running at 7.0 miles per hour and while walking at 3.5 miles per hour on a treadmill, Grade 8.9 per cent ${ }^{2}$ by methods described by Robinson (12). Other aspects of this study have been reported elsewhere $(3,13)$.

Results. Table $\mathrm{X}$ shows that during running ventilation starts higher but ends lower; as the run progresses ventilatory efficiency is lower at all intervals of run for N.C.A. Data from a group of younger men (14) are included for comparison and the N.C.A. patients differ even more from them.

During the walk there is a higher pulmonary ventilation and a lower ventilatory efficiency in N.C.A.

SUm MARY. Ventilation is higher in N.C.A. for moderate work than in controls, is higher in N.C.A. as hard work begins but becomes lower as hard work progresses. Ventilatory efficiency is

2 Referred to in previous Harvard Fatigue Laboratory publications as 8.6 per cent. 
TABLE $X$

Pulmonary ventilation and ventilatory efficiency

N.C.A. vs. controls

While running on a treadmill-7.0 miles per hour at $\mathbf{8 . 9}$ per cent grade, pulmonary ventilation in $\mathrm{ml}$. per kilo and min.

\begin{tabular}{l|c|c|c|c|c}
\hline \hline & Age & No. & 1-1 min. & $1-2$ min. & $2-3$ min. \\
\cline { 1 - 5 } Healthy men & 20 & 46 & 730 & 1,027 & 1,231 \\
Healthy men & 29 & 20 & 645 & 977 & 1,216 \\
N.C.A. & 28 & 20 & 829 & 1,037 & 1,108 \\
\hline
\end{tabular}

Ventilatory efficiency $\left(\frac{\mathrm{O}_{2} \text { consumed }}{\text { Ventilation }}\right)$

\begin{tabular}{l|c|c|c|c|c}
\hline & Age & No. & t-1 min. & 1-2 min. & $2-3$ min. \\
\cline { 2 - 6 } Healthy men & 20 & 46 & 5.34 & 4.90 & 4.23 \\
Healthy men & 29 & 20 & 5.29 & 4.59 & 3.92 \\
N.C.A. & 27 & 18 & 5.29 & 3.68 & 3.46 \\
\hline
\end{tabular}

While walking on a treadmill, 3.5 miles per hour, 8.9 per cent grade

\begin{tabular}{l|c|c|c}
\hline & No. & Ventilation & $\begin{array}{c}\text { Ventilatory } \\
\text { efficiency }\end{array}$ \\
\hline & & $\begin{array}{c}\text { ml. per kilo } \\
\text { and min. } \\
\text { Healthy men }\end{array}$ & 574 \\
N.C.A. & 20 & 657 & 5.1 \\
\hline
\end{tabular}

lower in N.C.A. than in healthy controls for moderate and hard muscular work.

\section{DISCUSSION AND SPECULATION}

In neurocirculatory asthenia, anxiety neurosis, or effort syndrome many respiratory symptoms occur in high incidence. They constitute a characteristic and therefore diagnostic feature of the disorder; the absence of such symptoms makes the diagnosis of N.C.A. improbable. The complete mechanism of these symptoms is unknown. It is of interest that when respiration is investigated objective abnormalities are found, just as when other symptoms of N.C.A. are investigated with objective methods (3), which demonstrates that the abnormalities are not all in the subjective sphere.

The abnormalities at rest and breathing oxygen are few; while breathing air at rest M.R.V. was higher; during exercise the abnormalities become more pronounced, the deviations from the normal becoming greater as rate and amount of excercise increase. This is of interest particularly since the patients' disability involves especially hard work.

Ventilation index was higher in N.C.A. than in controls. This was true, but to a lesser degree, in cases of "cardiac neurosis" described by Harrison (15) who felt that the differences were not noteworthy. The differences between N.C.A. and controls are more marked in this study, probably due to the fact, as suggested to us by Harrison (16), that his healthy controls were less fit than ours and our N.C.A. patients were sicker clinically than those he studied. In fact, this corresponds with a general scheme in which the most fit and youngest subjects show lowest values, the healthy men in the late twenties are next, N.C.A. higher, the most severe being highest (Table XI). ${ }^{10,15,17}$ Patients with heart disease, of course, are highest (10).

TABLE XI

Levels in ventilation index in various groups of healthy men and in N.C.A. patients

\begin{tabular}{|c|c|c|c|}
\hline \multirow{2}{*}{ Subjects } & \multirow{2}{*}{ No. } & \multicolumn{2}{|c|}{ Exercise } \\
\hline & & II & IV \\
\hline $\begin{array}{l}\text { Athletes (Harrison, 17) } \\
\text { Medical students (Harrison, 17) } \\
\text { Healthy soldiers } \\
\text { Under } 30 \text { years of age (Harrison, 10) } \\
\text { Cardiac neurosis (Harrison, 15) } \\
\text { Neurocirculatory asthenia }\end{array}$ & $\begin{array}{l}13 \\
41 \\
54 \\
10 \\
16 \\
55\end{array}$ & $\begin{array}{l}16.4 \\
17.3 \\
18.4 \\
20.8 \\
22.2 \\
23.2\end{array}$ & $\begin{array}{l}23.7 \\
28.6 \\
29.0 \\
34.8 \\
36.9\end{array}$ \\
\hline
\end{tabular}

The ventilation factor accounts for the high ventilation index. The ventilation is highest after exercise, disproportionately so in N.C.A. as compared with controls. This may be related to other evidence of increased oxygen debt in N.C.A. and high blood lactate after exercise $(3,5,13)$. It is possible that the higher blood lactate concentration during and after exercise in N.C.A. may participate as a stimulus to augmented ventilation. No crucial data are at hand that bear on these points. It is not known to what extent factors of physical training and patients' attitudes affect these results.

It is of further interest that the greater the stress or stimulus the greater and the more frequent the respiratory abnormality in N.C.A. This corresponds with patients' clinical history, with observations such as earlier ones made by one of us (White, 18) that running while wearing a gas mask was especially difficult and extremely abnormal in patients with effort syndrome and neurosis. The general rule that the greater the stimulus the more obvious the abnormality in N.C.A. is true of phenomena other than respiratory ones, for example, response to pain (3). 
There has been a certain amount of discussion as to the proper definition of dyspnea. Means (19) defines it as a "symptom that arises whenever in carrying on the respiratory function difficulty is encountered." He points out that "when, however, the respiratory organs do meet with embarrassment in the performance of their task, then not only do their movements enter the field of consciousness, but they enter it unpleasantly and produce discomfort, that is to say dyspnea." Meakins (20) states "dyspnea is the consciousness of the necessity for increased respiratory effort." Harrison (10) regards dyspnea as a subjective phenomenon purely. Wright (21) states that "when the breathing enters consciousness unpleasantly and produces discomfort it is called dyspnoea." Christie (22) takes exception to this point of view, feeling that dyspnea should describe "difficult, painful, bad, or disordered breathing. The word can therefore be used objectively as well as subjectively and the more elastic definition of dyspnea as breathing associated with effort is fully justified." $\mathrm{He}$ points out that if one adopts too rigidly the definition of dyspnea as a subjective complaint "the absurdity is admitted that the hysterical patient who shows no evidence of increased ventilation or respiratory embarrassment but complains of inability to get enough air into the lungs is truly dyspneic; while the patient with pneumonia who, though distressed, refuses to admit a feeling of breathlessness is not dyspneic."

It is not clear to us what the proper usage of the word dyspnea should be. If the word is used at all, however, it should be used uniformly to mean the same thing by all observers. It is clear from this study that the subjective feeling of shortness of breath and distress is not based entirely on the amount of ventilation, since N.C.A. patients feel more shortness of breath and distress for the same amount of ventilation than do controls. This is true in addition to the fact that for the same amount of work N.C.A. shows higher ventilation and ventilation index.

It is important, therefore, that the subjective complaints of shortness of breath, distress, and discomfort be considered as not identical with the phenomenon of increased respiratory volume. There is, it might be added, no definite evidence as yet as to what area or areas of the brain are associated with the localization of the subjective feelings of dyspnea.

The tendency of N.C.A. patients to react more to uncomfortable stimuli is present in other spheres of discomfort, such as thermal pain and uncomfortable hand gripping $(3,5)$, and is also evidenced in other functions such as pulse rate (3). These facts do not explain the phenomenon but make it important to realize that it is not an isolated one, since N.C.A. patients react more than do controls to other types of stimulus and with other systems.

We were not able to confirm the finding of low vital capacity in effort syndrome patients in whom similar studies of respiration were made (23). These observers reported vital capacity mean of $2,840 \mathrm{ml}$. in patients and $4,172 \mathrm{ml}$. in controls. It is possible that difficulty in checking vital capacity results in N.C.A. may account for this difference. We found that patients and controls had identical vital capacity values as determined by our strict technique, but patients took more trials for a check. Whether this was due to poor motivation, poor voluntary control of respiratory movements, different type or stage of illness studied, or to other factors is unknown.

The evidence of poor ventilatory efficiency corresponds interestingly, although it may not explain, another symptom which patients have which is that they "can't get in enough air" or that "air doesn't seem to do as much good as it should."

\section{CONCLUSIONS}

1. In neurocirculatory asthenia, effort syndrome, or anxiety neurosis there are many symptoms referable to respiration.

2. At rest, while breathing oxygen, patients show rapid respiratory rate and abnormally shallow breathing.

3. While breathing air, minute respiratory volume is significantly higher in N.C.A. at rest and during moderate exercise than in controls, becoming lower as hard exercise progresses.

4. The greatest disproportion in pulmonary ventilation between patients and controls occurs in the early minutes of the recovery period after exercise, suggesting a relation to the high blood lactate and oxygen debt mechanism.

5. Vital capacity is normal in neurocirculatory asthenia. 
6. Ventilation index, an objective correlate of dyspnea, is high in neurocirculatory asthenia.

7. The incidence and degree of dyspnea are out of proportion to the severity of exercise, the pulmonary ventilation, or the ventilation index in N.C.A.

8. Ventilatory efficiency is low in neurocirculatory asthenia both in moderate and in severe muscular exercise.

\section{BIBLIOGRAPHY}

1. DaCosta, J. M., On irritable heart; a clinical study of a form of functional cardiac disorder and its consequences. Am. J. M. Sc., 1871, 61, 17.

2. Lewis, T., The Soldier's Heart and the Effort Syndrome. Shaw and Sons, Ltd., London, 1940.

3. Cohen, M. E., Johnson, R. E., Chapman, W. P., Badal, D. W., Cobb, S., and White, P. D., A study of neurocirculatory asthenia, anxiety neurosis, and effort syndrome. Final report to the Committee on Medical Research of the Office of Scientific Research and Development under Contract OEM-cmr 157, 1946.

4. Brouha, L., Graybiel, A., and Heath, C. W., The step test: simple method for measuring physical fitness for hard muscular work in adult man. Rev. Canad. de Biol., 1943, 2, 86.

5. Cohen, M. E., Johnson, R. E., Cobb, S., Chapman, W. P., and White, P. D., Studies of work and discomfort in patients with neurocirculatory asthenia. J. Clin. Invest., 1944, 23, 934.

6. Hawk, Philip B., and Bergeim, Olaf, Practical Physiological Chemistry. Eleventh Edition. The Blakiston Company, Philadelphia, 1937.

7. Roth Metabolimetric Chart. Warren E. Collins, Boston. From Dubois and Dubois, Arch. Int. Med., 1916, 17, 865.

8. Peabody, F. W., and Wentworth, J. A., IV. The vital capacity of the lungs and its relation to dyspnea. Arch. Int. Med., 1917, 20, 443.

9. Peabody, F. W., and Sturgis, C. C., The relation of dyspnea to the maximum minute-volume of pulmonary ventilation. Arch. Int. Med., 1922, 29, 236.

10. Harrison, T. R., Turley, F. C., Jones, E., and Calhoun, J. A., Congestive heart failure. $\mathrm{X}$. The measurement of ventilation as a test of cardiac function. Arch. Int. Med., 1931, 48, 377.

11. Thomson, K. J., and Cohen, M. E., Studies on the circulation in pregnancy. II. Vital capacity observations in normal pregnant women. Surg. Gyn. and Obst., 1938, 66, 591.

12. Robinson, S., Experimental studies of physical fitness in relation to age. Arbeitsphysiol., 1938, 10, 251.

13. Cohen, M. E., Johnson, R. E., Consolazio, F., and White, P. D., Low oxygen consumption and low ventilatory efficiency during exhausting work in patients with neurocirculatory asthenia, effort syndrome, anxiety neurosis. J. Clin. Invest., 1946, 25, 920.

14. Heath, C. W., Unpublished data.

15. Harrison, T. R., Harris, S., Jr., and Calhoun, J. A., Studies in congestive heart failure. XVI. The clinical value of the ventilation test in the estimation of cardiac function. Am. Heart J., 1931, 7, 157.

16. Harrison, T. R., Personal communication.

17. Turley, F. C., and Harrison, T. R., Respiratory measurements as affected by smoking and by athletics. Am. J. M. Sc., 1932, 183, 702.

18. White, P. D., Observations on some tests of physical fitness. Am. J. M. Sc., 1920, 159, 866.

19. Means, J. H., Dyspnoea. Medicine, 1924, 3, 309.

20. Meakins, J. C., Dyspnea. J. A. M. A., 1934, 103, 1442.

21. Wright, S., Applied Physiology (6th Edition). Oxford, New York, 1937.

22. Christie, R. V., Dyspnoea : a review. Quart. J. Med., 1938, 7, 421.

23. Jones, M. S., and Scarisbrick, R., A comparison of the respiration in patients with effort syndrome and in normal subjects. War Med., 1942, 2, 901. 